\title{
Oil Pool Fire Experiment
}

\author{
TAKAAKI YAMAGUCHI and KENJI WAKASA \\ Petroleum Association of Japan \\ 1-9-4, Ohtemachi, Chiyoda-ku \\ Tokyo, 100 Japan
}

\section{ABSTRACT}

It is important to know the behavior of a large-scale oil pool fire, so a large-scale oil pool fire experiment was carried on in JAPAN on May 30, 1981. It was carried out by filling excavated storage tanks measuring $30 \mathrm{~m}, 50 \mathrm{~m}$ and $80 \mathrm{~m}$ in diameter each with water of about $200 \mathrm{~mm}$ in depth, floating kerosene to a depth of about $20 \mathrm{~mm}$ above the water and burning the kerosene.

Measurements were made on the flame temperature, radiant heat, partial radiant heat, burning rate of a hydrocarbon pool fire, composition of gaseous combustion products, naturally-induced airflow velocity and flame shape, seven items in a11.

The experiment results clearly indicate that the results of a small-scale experiment on a storage tank whose diameter is less than $10 \mathrm{~m}$ cannot be extrapolated to a large-scale oil pool fire.

\section{INTRODUCTION}

The oil pool fire experiment conducted this time was mainly aimed at clarifying the behavior of a large-scale oil pool fire with emphasis on the analogy due to the sizes of storage tanks, and at examining the validity of the conventional danger evaluation based on the extrapolation of the results of a sma11-scale experiment.

The experiment was conducted at the Higashi-Fuji Exercise Field of the Ground Self-Defense Force in Gotenba City, Shizuoka Prefecture on May 30, 1981 with the participation of the Petroleum Association of Japan and Petrochemical Industry Association and the cooperation of Shizuoka Prefecture.

Formulation of the plan, guidance to execution and analysis of results of the experiment were commissioned to the Safety Engineering Association. The Association established an Oil Pool Fire Experiment Committee consisting of 13 experts to accomplish the task.

\section{Preparation}

The experiment was carried out using excavated storage tanks of $30 \mathrm{~m}, 50 \mathrm{~m}$ and $80 \mathrm{~m}$ in diameter and by burning kerosene. The specifications and arrangement of the fuel tanks are shown in $\mathrm{Fig}$. 1. Since the fuel was floated on the 
water in the tank, the bottom of each fuel tank was covered with polyethylene sheeting to prevent water leakage.

Kerosene was used as fuel for the following reasons: If crude oil with a wide boiling-point range had been used, it would have caused changes in fluid composition due to evaporation during combustion, and no regular combustion would be obtainable, resulting in difficulty of comparison of combustion characteristics. It was desirable to have a thicker layer of fuel in order to prolong the steady state of combustion, but it was determined to use a fuel layer of about $20 \mathrm{~mm}$ due to various restrictions, and this layer of fuel was floated on the surface of water of about $200 \mathrm{~mm}$ in depth.

1. Fuel tank specifications



2. Fuel tank layout

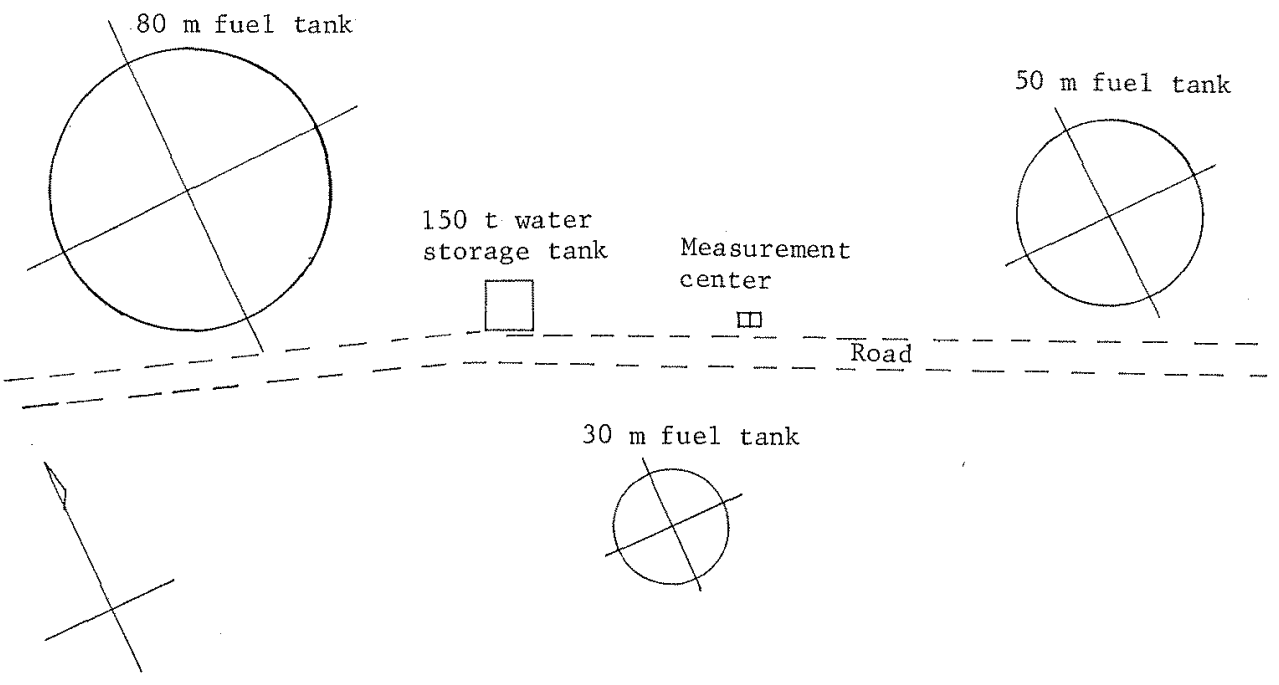

FIGURE 1. Specifications and layout of fuel tanks 
Ignition

Due to the reasons that kerosene with a higher ignition point was used as fuel and it was necessary to cause the ignited fire to grow into a complete conflagration within as short a time as possible, small amounts of naphtha were made to flow out of several points on the oil surface and ignited electrically using ignition balls.

1. Ignition position

Since the thickness of kerosene was $20 \mathrm{~mm}$ and thin, it was necessary to wholly burn kerosene for a short time after ignition so that the whole burning time would be made long.

After pre-test results, it was found that liquid surface falling speed was about $2.1 \mathrm{~mm} / \mathrm{min}$ and fire propagation speed was 3 to $4 \mathrm{~m} / \mathrm{min}$.

The fire became a conflagration in 3 minutes after ignition.

Kerosene consumption until then was thought to be about $2 \mathrm{~mm}$ on the average for all tanks. Kerosene of $18 \mathrm{~mm}$ or above was consumed when a conflagration occurs.

Since fire propagation speed was 3 to $4 \mathrm{~m} / \mathrm{m}$, it was assumed that fire would expand to 9 to $12 \mathrm{~m}$ in 3 minutes.

The position and number of ignition points were determined, so that any parts of the tank can be within about $10 \mathrm{~m}$ from the ignition position. As a result, it was determined that $50 \mathrm{~m}$ tank should ignite at 4 points and $80 \mathrm{~m}$ tank would ignite at 11 points. It was determined that the $30 \mathrm{~m}$ tank should ignite at central 1 point in order to measure the fire propagation speed.

2. Ignition facilities

Since it was difficult to ignite directly to kerosene, it was determined that ignition should be made by a small quantity of naphtha and ignition balls to the extent of which influence would not given to the burning properties of kerosene.

The head tank of ignition naphtha was installed at the place 5 to $10 \mathrm{~m}$ away from the edge of each tank. The pre-test was made so that the naphtha quantity, which flowed out of respective outlets, would be about $500 \mathrm{ml} / \mathrm{min}$.

The height of the head tank was set so that its bottom would be $1 \mathrm{~m}$ higher from the outlet. Outlets, to which naphtha would flow from the head tank, were installed to the ignition equipment. They were connected with the PVC tube. Outlets were set facing upward direction at about $5 \mathrm{~cm}$ above the liquid.

The circumference of outlets was covered with cotton cloth hung from above. When the stop valve opened, which had been installed to the head tank containing naphtha, naphtha flowed out of outlets. Part of naphtha was impregnated into cotton cloth and remaining naphtha was mixed with kerosene in the tank. Ignition balls were set into cotton cloth so that naphtha would not be directly placed. The switch of ignition balls was installed at D/4 outside the tank and ignition balls of respective tanks were designed to be operated by setting one switch. Naphtha of $2500 \mathrm{ml}$ per outlet was placed 
into the head tank so that naphtha of $500 \mathrm{ml}$ for each minute per outlet would flow for 5 minutes.

The number of head tanks was 30 . One head tank each was installed for $50 \mathrm{~m}$ tank and 2 head tanks were installed for $80 \mathrm{~m}$ tank.

\section{Ignition procedures}

PVC tubes were made full of naphtha beforehand so that naph tha would flow out from outlets at the same time when the valve was opened. The valve of the head tank was opened 1 minute before ignition. One minute after naphtha was discharged, the switch of ignition balls was turned oN and ignition balls were caused to generate.

According to this operation, ignition balls would be ignited, naphtha, which was impregnated into cotton cloth, would burn, kerosene mixed with naphtha would be lit and, further, fire would propagate to kerosene of the whole tank.

\section{Measurement}

Measurements were made on many items including the flame temperature, radiant heat, partial radiant heat, burning rate of the hydrocarbon pool fire, composition of gaseous combustion products, naturally-induced airflow velocity and flame shape.

\section{Flame temperature measurement}

Temperatures in the liquid and on and above the liquid surface during combustion were measured by installing sheath-type thermocouples at six locations in the center of each tank and four locations at positions of $D / 8$, $\mathrm{D} / 4$, and $\mathrm{D} / 2$ ( $\mathrm{D}$ : tank diameter) from the center, 18 locations in all.

2. Radiant heat measurement

Radiant heat from the flames was measured outside the fuel tank and on the liquid surface in the fuel tank. Measurements were made by installing radiant heat meters at positions of $1 \mathrm{D}, 2 \mathrm{D}, 3 \mathrm{D}$, and $4 \mathrm{D}$ from the center in each tank for measuring outside the fuel tank, and by installing liquid-level radiant heat meters at three points in the $80 \mathrm{~m}$ tank and at one point each in $50 \mathrm{~m}$ and $30 \mathrm{~m}$ tanks for measuring on the 1iquid surface.

3. Partial radiant heat measurement

To find out the magnitudes of radiant heat from various portions of flames, partial radiant heat was measured by installing radiant heat meters, whose heat receiving surface was partially shielded, at a position of $2 \mathrm{D}$ from the center of each tank.

4. Measurement of burning rate of hydrocarbon pool fire

The burning rate of fuel was measured by the liquid level descending rate. The average descending rate of the entire liquid level was measured at one point in each tank, while regional liquid level descending rates were measured at four points in the $80 \mathrm{~m}$ tank, two points in the $50 \mathrm{~m}$ tank and one point in the $30 \mathrm{~m}$ tank. 
Further, a video camera was installed at the center of the $50 \mathrm{~m}$ tank to monitor the liquid level condition and liquid level descending rate during combustion.

5. Measurement of composition of gaseous combustion products

To find out the detailed burning condition during an oil conflagration, gases on the liquid surface and in the flames were sucked in and collected from seven points in each tank, and concentrations of carbon monoxide, carbon dioxide, hydrocarbon and oxygen contained therein were analyzed by gas chromatograph. In addition, oxygen concentration was continuously measured using an oxygen concentration meter separately from the gas chromatograph.

6. Measurement of naturally-induced airflow velocity

The velocity of the naturally induced airflow generated by the oil fire was monitored by propeller and bilam type anemometers installed at eight points each in each tank to measure the wind direction and velocity near the edge of each tank.

7. Flame shape measurement

To clarify the behavior of an oil conflagration including the height and shape of flames, the burning state in each tank was recorded by a $16 \mathrm{~mm}$ movie camera and a video camera.

Results

Experiments with the $30 \mathrm{~m}$ tank (Experiment No. 1) and $50 \mathrm{~m}$ tank (Experiment No. 2) were carried out as planned under conditions of near calm, but the experiment with the $80 \mathrm{~m}$ tank (Experiment No. 3) was conducted under windy conditions, and some points which were slightly different from the original plan such as deviation of the oil layer on the water surface occurred.

The present combustion experiments used unprecedently large-scale storage tanks, and measurements also employed new techniques such as observation of liquid level variation by a submerged video camera, and measurements of the regional liquid level descending rate and partial radiant heat of flames, thereby obtaining many valuable experiment results. Major findings from the experiments are enumerated below.

1. In the 1st experiment, naphtha burned up at the same time when ignition balls switch was turned $O N$, and just after that, the liquid surface began burning. In the 2nd experiment, cotton naphtha at al1 4 points burned up and the liquid surface began burning simultaneous when ignition balls switch was turned ON. In the 3rd experiment, cotton cloth naphtha was ignited at only 6 points due to strong wind.

Three points out of them were set on the water surface where there was no oil, because the oil surface inclined to part of the burning tank due to the wind; hense fire propagation did not occur to the liquid surface and the fire was put out immediately after the flow of naphtha. Where the points were set on the liquid surface, the liquid surface was ignited immediately. In the 1 st and 2nd experiments, a conflagration was made in about 3 minutes as scheduled. In the $3 \mathrm{rd}$ experiment, propagation down the wind side was in 2 to 3 minutes. The whole surface on the wind side where there was kerosene burned in about 5 minutes after ignition. 
2. As analysis results of burning gas constituents, only 1 time of the result concerning the $80 \mathrm{~m}$ tank was shown. This was due to the fact that since 1) kerosene in the $80 \mathrm{~m}$ tank was blown away towards the wind side by the wind, 2) about $1 / 2$ of the kerosene surface only burned, 3) the kerosene surface severely inclines, 4) the sample introduction section completely was exposed in the air, measurement became meaningless; hence this part was omitted.

In the continuously recorded results of oxygen concentration in respective tanks, it was observed that turbulence was caused by cock operation for sampling. From the positional relationship between the fire condition at nearly the time when sampling was made and the sample introduction section, it can be thought that in the 30 and $50 \mathrm{~m}$ tanks, gas constituents in the flames can be sampled, but in the $80 \mathrm{~m}$ tank, the sample introduction section is exposed very much in the air. When we consider the positional relation between the condition of the fire nearly at the time, when sampling is made, and the sample introduction section, we find that we have probably been able to sample gas constituents in the fire for at $30-\mathrm{m}$ and $50-\mathrm{m}$ tanks, but the sample introduction section is quite extensively exposed to air at the $80 \mathrm{~m}$ tank.

3. Light emission of the flames was not dependent upon the sizes of storage tanks, but became the maximum at a height 0.8 to 1.0 times the tank diameter length. Such flames developed a pattern of respiration with a period of several seconds, and the period became longex as the storage tank size increased.

4. The maximum temperature of the flames was obtained near the center of the tank and reached 1,400 to $1,800^{\circ} \mathrm{C}$. This value did not vary with the sizes of tanks, but was slightly higher than that of a crude oil fire.
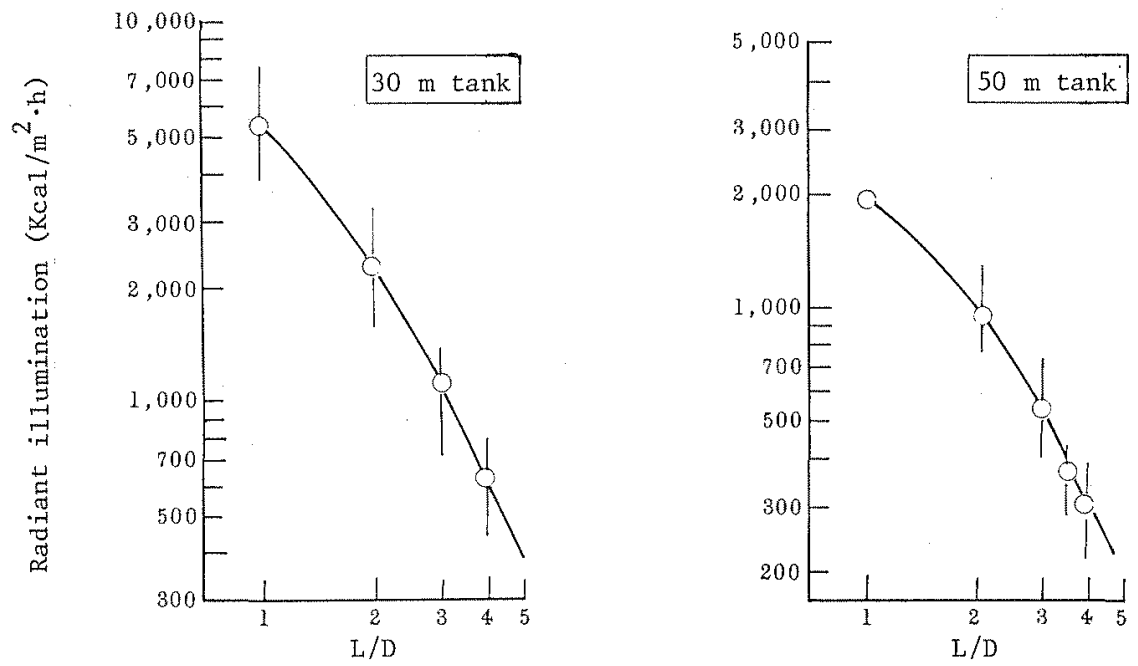

FIGURE 2. Relation between radiant heat and dimensionless distance under calm conditions ( $L$ is the distance from tank center to radiation meter) 
5. The receiving quantity of radiant heat along the ground surface-when compared with dimensionless distance $\mathrm{L} / \mathrm{D}$ which was obtained by dividing the distance from the tank center L by storage tank diameter D--suddenly dropped as $L / D$ increased, and the heat receiving quantity, the dimensionless distance being equal, did not collate with the value obtained by conventional predictive calculation, and sharply decreased as the size of the tank increases.

6. Oil level descending rate due to combustion was about $4.7 \mathrm{~mm} / \mathrm{min}$ on the average of the entire oil surface, and did not appear to be dependent on tank sizes. On the other hand, the regional liquid level descents varied with locations and time within the range of 2 to $7 \mathrm{~mm} / \mathrm{min}$, and were related to the movements of flames near the oil surface.

7. Naturally-induced airflow velocity necessary for burning was greater at the position higher than the ground surface and indicated the value of several $\mathrm{m} / \mathrm{s}$. This rate dropped as the tank size increased and showed cyclic variation as the respiration of the flames. Further, the oil surface developed ripples even during calm owing to this naturally-induced airflow by combustion.

8. Near the liquid level at the tank center during a conflagration, oxygen supply was minimal, and oxygen concentration became higher at a position high above the liquid level. As a result, oxygen deficiency occurred at the center portion, and steam which had evaporated from the liquid surface developed pyrolysis and generated low-molecular-weight combustible gases such as methane.

9. During combustion, heat transfer from flames to the liquid surface was mainly performed by radiant heat transfer, and convective heat transfer was on1y about $10 \%$ of the radiant heat transfer.

10. Slanting of flames due to winds was at about $30^{\circ}$ from horizontal at the lower part of the flames in Experiment No. 3 in which wind velocity varied between 5 to $10 \mathrm{~m} / \mathrm{s}$. This slanting angle increased to about $70^{\circ}$ at the upper part of the flames.

11. The wind did not greatly affect the maximum temperature of flames. Radiant heat from flames when it was windy showed a great difference depending upon the wind receiving direction. It became the maximum in the rightangle direction with the wind direction and the minimum on the windward side.

\section{Genera1 Conclusions}

These results will be analyzed in detail in the future. Some items of the experiment results are important, because they suggest that the results of the smal1-scale experiment with a tank having a diameter of 1 ess than $10 \mathrm{~m}$, as they are, cannot be extrapolated to an oil conflagration. In particular, the finding concerning radiant heat in Item 3 . indicates that since the heat receiving quantity decreases as the storage tank size increases, the dimensionless distance being equal, it is not appropriate to compare radiation heat danger uniformly by the dimensionless distance and that the calculation of radiant heat by the conventionally used danger prediction calculation method requires reassessment, because such calculation gives over-estimation of several times as much as the measured value, thereby suggesting that the said finding has an important meaning in practice. 
The measured values of radiant heat obtained by the present experiment are compared with calculated values obtained by the conventional calculation method as follows:

Measured and calculated values of radiant heat intensity

\begin{tabular}{|c|c|c|c|c|}
\hline \multirow{2}{*}{$\begin{array}{l}\text { Burnt tank } \\
\text { diameter }\end{array}$} & \multirow{2}{*}{$\begin{array}{l}\text { Distance from burnt } \\
\text { tank center }\end{array}$} & \multicolumn{2}{|c|}{ Radiant heat intensity } & \multirow{2}{*}{$\begin{array}{c}\text { Ratio } \\
\mathrm{Em} / \mathrm{Ec} \\
\%\end{array}$} \\
\hline & & $\begin{array}{l}\text { Measured value } \\
\text { Em* Kcal } / \mathrm{m}^{2} \mathrm{~h}\end{array}$ & $\begin{array}{l}\text { Calculated value } \\
\text { Ec Kcal } / \mathrm{m}^{2} \mathrm{~h}\end{array}$ & \\
\hline $30 \mathrm{~m}$ & $\begin{array}{l}1 D \\
2 D \\
3 D \\
4 D\end{array}$ & $\begin{array}{r}5,400 \\
2,300 \\
1,100 \\
620\end{array}$ & $\begin{array}{r}10,540 \\
4,300 \\
2,180 \\
1,290\end{array}$ & $\begin{array}{l}51 \\
53 \\
50 \\
48\end{array}$ \\
\hline $50 \mathrm{~m}$ & $\begin{array}{l}1 D \\
2 D \\
3 D \\
4 D\end{array}$ & $\begin{array}{r}1,900 \\
960 \\
540 \\
310\end{array}$ & $\begin{array}{r}10,540 \\
4,300 \\
2,180 \\
1,290\end{array}$ & $\begin{array}{l}19 \\
22 \\
25 \\
24\end{array}$ \\
\hline
\end{tabular}

* Average during calm

The present experiment is expected to increase in value as research progress in this field, and actual application of the experiment results will play important roles in the practical and research aspects in the future.

\section{REFERENCES}

1. Japan Society for Safety Engineering: The Report of the oil Pool Fire Experiment, J.S.S.E., Yokohama, Japan, 1981.

2. Yumoto, T.: Journal of Japan Society for Safety Engineering, J.S.S.E., Yokohama, Japan, 10: 3, 143, 1971 .

3. Yumoto, T.: Journal of Japan Society for Safety Engineering, J.S.S.E., Yokohama, Japan, 16: I, 58, 1977.

4. Yumoto, T., Nakagawa, N., and Sato, K.: Journal of Japan Society for Safety Engineering, J.S.S.E., Yokohama, Japan, 21: 1, 30, 1982.

5. Yamaguchi, T., Konishi, S., and Yamamoto, Y.: Journal of Japan Society for Safety Engineering, J.S.S.E., Yokohama, Japan, 21: 4, 215, 1982.

6. Kashio, T., and Akita, K.: Proceedings of the 13th Symposium of Safety Engineering, Japan Society for Safety Engineering, Japan, 81, 1983 . 